\section{TUBERCULAR INFECTION IN SYSTEMIC LUPUS ERYTHEMATOSUS PATIENTS-A REPORT FROM AN ENDEMIC COUNTRY}

${ }^{1} \mathrm{MF}$ Ahmmed, ${ }^{2} \mathrm{MN}$ Islam*, ${ }^{3} \mathrm{~N}$ Ferdous, ${ }^{4} \mathrm{JJH}$ Rasker. ${ }^{1} \mathrm{BSMMU}$, Rheumatology, Dhaka, Bangladesh; ${ }^{2} B S M M U$ and MOACandRC, Rheumatology, Dhaka, Bangladesh; ${ }^{3}$ MOACandRC, Rheumatology, Dhaka, Bangladesh; ${ }^{4}$ University of Twente, PsychologyHealth and Technology, Enschede, Netherlands Antilles

\subsection{6/lupus-2017-000215.356}

Background and aims The tubercular infections (TB) are most important cause of morbidity and mortality in SLE patients worldwide and an ongoing alarming issue in developing countries. This study was aimed to observe frequency and risk factors of tuberculosis in SLE patients.

Methods This observational study was carried out in SLE clinic of BSMMU, Bangladesh. A total 230 consecutive SLE patients were enrolled. Patient's clinical characteristics, history of TB, SLEDAI score, cumulative doses of immunosuppressants were recorded. In clinically suspected cases tuberculin test, chest X-ray, spot and first morning sputum for AFB, Gene Xpert MTB/RIF, ADA, FNAC and tissue biopsy were requested along with routine tests. The multivariate logistic regressions were done for risk factors. Ethical clearance was obtained from IRB of BSMMU.

Results Out of 230 patients TB was documented in $23(10 \%)$ subjects. Among TB cases 16 women and 7 men. Mean age of patients was $27.56 \pm 9.3$ years and mean duration of occurrence of tuberculosis after SLE diagnosis was $4.26 \pm 5.38$ years. Cough, night sweat, fever, anorexia were significant presenting features. Present and past TB was observed in 10 and 13 cases respectively. Fifteen and 8 patients had pulmonary and extra pulmonary $\mathrm{TB}$ respectively. Organ involvement pattern was multi-lobed lungs, joint, meninges, lymph nodes, peritoneum and pleura. None had drug resistance. Active disease (SLEDAI score), intake of prednisolone $>500 \mathrm{mg}$ were notable risk factors.

Conclusions Frequency of tuberculosis was high (10\%) in SLE patients. Awareness including prevention of flares and judicious use of steroids might reduce the rate of $\mathrm{TB}$.

\section{INCREASED PERIPHERAL CD8 T CELL RESPONSES IN SLE BY LOW-DOSE IL-2 TREATMENT}

R Zhang*, J He, X Sun, C Li, Y Gan, Y Zou, Z Li. Peking University People's Hospital, Department of Rheumatology and Immunology, Beijing, China

\subsection{6/lupus-2017-000215.357}

Background and aims CD8 $\mathrm{T}$ cell responses to viral pathogens is crucial for the prompt resolution of acute infections. SLE patients are more likely to have infections due to long-term glucocorticoid and immunosuppressive agent intake. The present study is to evaluate the potential anti-infection effect of low-dose IL-2 in SLE patients.

Methods Peripheral blood mononuclear cells from nine refractory SLE patients and 9 health controls (HCs). The disease activities were evaluated by rheumatologist. The frequencies of $\mathrm{T}$ cell subsets were assayed by flow cytometry. Virus-specific CD8 $\mathrm{T}$ cells responses were determined based on TNF-a IFN$\mathrm{g}$ and Granzyme B producing CD8 $\mathrm{T}$ cells upon CMV-EBVFlu(CEF) viral peptide pool stimulation.
Results Most patients showed good clinical responses after low-dose IL-2 treatment (7 out of 9). Clinical improvement was observed with SIR-4 response (6 out of 9), improved complement 3 and 4 serum level (9 out of 9 ) and decreased anti-ds-DNA serum level (8 out of 9 ). Functional profiling of CD8 $\mathrm{T}$ cells in low-dose IL-2 treated patients revealed increased frequencies of CEF viral peptide specific $\mathrm{TNF}_{-}{ }^{+}$ and Granzyme- $\mathrm{B}^{+} \mathrm{CD} 8 \mathrm{~T}$ cells. Moreover, these patients showed stronger antigen-specific response demonstrated by an increased stimulated/non-stimulate TNF-a-producing CD8 T cells proliferation fold. Compared with HC, SLE patients showed significantly lower frequencies of CEF specific Granzyme-B producing CD8 T cell, and low-dose IL-2 significantly increased the frequency of these Granzyme- $\mathrm{B}^{+} \mathrm{CD} 8 \mathrm{~T}$ cells in SLE patients.

Conclusions Virus-specific antigen-specific CD8 T cell response could be enhanced upon this treatment which might be potentially valuable in anti-infection in SLE.

\section{A SINGLE CENTRECENTER EXPERIENCE OF RITUXIMAB TREATMENT IN 79 PATIENTS WITH SYSTEMIC LUPUS ERYTHEMATOSUS}

B Artim-Esen, Ç Çetin, M Metban, M Erdugan, E Oguz, A Gul, L Ocal, M Inanc*. Istanbul University - Istanbul Faculty of Medicine, Internal medicine- division of rheumatology, Istanbul, Turkey

\subsection{6/lupus-2017-000215.358}

Background and aims B-cell-targeted therapies have been promising new treatments for SLE. Herein, we aimed to analyse the effects of Rituximab in lupus patients with involvement of different domains.

Methods This is an analysis of 79 lupus patients treated with rituximab at the rheumatology outpatient clinic. Patient features, previous and concomitant treatments, baseline clinical and serological characteristics, treatment response at 3 and 6 months, number of cycles, flares, infections and infusion reactions were analysed. Disease activity was assessed using SLE disease activity index (SLEDAI) and treatment response was defined according to the system involved.

Results 37 patients received Rituximab for lupus nephritis (LN), 15 for thrombocytopenia and/or autoimmune hemolytic anaemia (AIHA), 12 for arthritis, 7 for vasculitis and 8 for general activity. Majority of the patients received one or two cycles of Rituximab. The reason of further cycles was maintenance in $40.5 \%$ of patients, non-remission in $50 \%$ and flare in $9.5 \%$. Highest complete response (CR) rate at the $6^{\text {th }}$ month was within the general disease activity group followed by the arthritis group. Comparison of treatment response between classIV and V LN revealed a a significantly higher number of CR in class IV at the $6^{\text {th }}$ month of treatment.

Comparison of SLEDAI score, steroid dose, anti-dsDNA positivity and complement levels between baseline and at the $6^{\text {th }}$ month favoured treatment. There were 9 infusion reactions and 12 infections.

Conclusions Rituximab remains as a therapeutic option, especially in severe and refractory cases. Safety profile is good but infusion reactions may represent a problem. 